\title{
Natural history of bleeding and characteristics of early bleeders among warfarin initiators - a cohort study in Finland
}

This article was published in the following Dove Press journal:

Clinical Epidemiology

5 February 2016

Number of times this article has been viewed

\author{
Maria Rikala' \\ Helena Kastarinen ${ }^{1,2}$ \\ Pekka Tiittanen' \\ Risto Huupponen ${ }^{1,3}$ \\ Maarit Jaana Korhonen 1,4,5 \\ 'Department of Pharmacology, Drug \\ Development and Therapeutics, \\ University of Turku, Turku, ${ }^{2}$ Social \\ Insurance Institution, Regional \\ Office for Eastern and Northern \\ Finland, Kuopio, ${ }^{3}$ Unit of Clinical \\ Pharmacology, Turku University \\ Hospital, ${ }^{4}$ Department of Public \\ Health, University of Turku, Turku, \\ Finland; ${ }^{5}$ Division of Pharmaceutical \\ Outcomes and Policy, UNC Eshelman \\ School of Pharmacy, The University \\ of North Carolina at Chapel Hill, NC, \\ USA
}

Aims: The demand for oral anticoagulant therapy will continue to increase in the future along with the aging of the population. This study aimed to determine the rate of bleeding requiring hospitalization and to characterize early bleeders among persons initiating warfarin therapy. Characterization of those most susceptible to early bleeding is important in order to increase the safety of warfarin initiation.

Patients and methods: Using data from nationwide health registers, we identified persons initiating warfarin therapy between January 1, 2009 and June 30, 2012, n=101,588, and followed them until hospitalization for bleeding, death, or administrative end of the study (December 31, 2012). We defined early bleeders as persons with a bleeding requiring hospitalization within 30 days since warfarin initiation.

Results: The rate of hospitalization for bleeding during a median follow-up of 1.9 years was $2.6 \%$ per person-year ( $95 \%$ confidence interval [CI] $2.5 \%-2.7 \%$ ), with a peak within the first 30 days of warfarin initiation (6.5\% per person-year, 95\% CI $6.0 \%-7.1 \%)$. In a multivariable Cox proportional hazards regression analysis, early bleeders were characterized by prior bleeding ( $<180$ days before initiation, hazard ratio $[\mathrm{HR}]=13.7,95 \%$ CI 10.9-17.1; during 180 days -7 years before initiation, $\mathrm{HR}=1.48,95 \% \mathrm{CI} 1.15-1.90)$, male sex $(\mathrm{HR}=1.32,95 \% \mathrm{CI}$ 1.10-1.57), older age ( $\mathrm{HR}=1.13,95 \%$ CI 1.04-1.22, per 10-year increase), venous thrombosis (HR $=1.83,95 \%$ CI 1.44-2.34), pulmonary embolism (HR $=1.46,95 \%$ CI 1.11-1.91), alcohol abuse (HR $=1.59,95 \%$ CI 1.08-2.35), rheumatic disease (HR $=1.40,95 \%$ CI $1.07-1.83$ ), and exposure to drugs with dynamic interaction mechanism with warfarin ( $\mathrm{HR}=1.43,95 \% \mathrm{CI}$ 1.20-1.71). In age-adjusted models, Charlson comorbidity index and number of drugs predicted a graded increase in the hazard of early bleeding.

Conclusion: The rate of hospitalizations for bleeding peaked in the beginning of warfarin therapy. Early bleeders were characterized by venous thrombosis, pulmonary embolism, and factors that increase bleeding risk without affecting the international normalized ratio.

Keywords: bleeding, comorbidity, hemorrhage, incidence, warfarin

\section{Introduction}

Vitamin K antagonists, especially warfarin, have traditionally been a cornerstone of anticoagulation therapy in the prevention and treatment of thromboembolic events. The main indication for warfarin therapy is atrial fibrillation ( $40 \%-65 \%$ of patients), followed by venous thrombosis, pulmonary embolism, and heart valve replacement. ${ }^{1-4}$ Despite its well-established efficacy, ${ }^{5,6}$ warfarin therapy also involves a substantial risk of bleeding. In observational studies representing real-world clinical practice, the incidence of bleeding ranges from $1.9 \%$ to $7.6 \%$ per person-year (PY) among patients with atrial fibrillation receiving warfarin therapy., $4-16$
Correspondence: Maarit Jaana Korhonen Department of Pharmacology, Drug Development and Therapeutics, University of Turku, Kiinamyllynkatu I0, 20520 Turku, Finland

Tel +35840357208I

Email maakor@utu.fi 
The incidence of bleeding has been shown to peak in the beginning of warfarin therapy, ${ }^{11,17}$ being the highest during the first month after warfarin initiation. ${ }^{11}$ The early peak may arise from early attrition of those most susceptible to bleeding. ${ }^{18}$ In addition, it may be related to difficulty to achieve the narrow therapeutic range (international normalized ratio [INR] 2-3). Specifically, warfarin dose-response is influenced by many factors, such as patient's age, diet, and various drugs and comorbidities that may alter warfarin metabolism. ${ }^{19}$ In addition, polymorphisms in CYP2C9 and VKORCl genes have an important contribution to warfarin dose-response. ${ }^{20}$ While INR above therapeutic range (INR $>3$ ) is a significant risk factor for bleeding, ${ }^{21}$ more than half of bleeding events occur within or below therapeutic range. ${ }^{22,23}$ Other factors, such as comorbidities and drugs, that increase bleeding risk without altering warfarin metabolism or activity of coagulation factors can contribute to these events; therefore, they cannot be avoided by INR monitoring and subsequent changes in warfarin dosing. Characterization of those most susceptible to early bleeding is important in order to increase the safety of warfarin initiation.

In this nationwide population-based cohort study, we examined the rate of serious bleeding, defined as bleeding requiring hospitalization, among noninstitutionalized Finnish persons initiating warfarin therapy over up to 4 years of follow-up. In addition, we characterized persons with an early bleeding requiring hospitalization in terms of comorbidities and exposure to interacting drugs.

\section{Patients and methods}

\section{Setting and data sources}

We conducted a nationwide population-based cohort study among noninstitutionalized Finnish persons initiating warfarin therapy between January 1, 2009, and June 30, 2012. We followed the initiators from the warfarin initiation date until December 31, 2012. We assembled the data by linking nationwide health registers maintained by the Social Insurance Institution (SII) and the National Institute for Health and Welfare (THL). The SII provided data on dispensed prescription drugs, demographics, dates of death, special reimbursements, and long-term institutional care ( $>90$ days of uninterrupted stays in public nursing homes or hospitals). The THL provided data on hospitalizations.

The Prescription Register includes information on reimbursed prescription drugs dispensed to community-dwelling residents of Finland. ${ }^{24}$ The information on drug use in public nursing homes and hospitals is supplied by the service provider and, therefore, not covered by the Prescription Register.
For each reimbursed drug, the Prescription Register contains Anatomical Therapeutic Chemical classification code, ${ }^{25}$ dispensing date, strength, and quantity dispensed. No structured information on prescribed dose, duration of therapy, or indication is recorded. Furthermore, the Prescription Register contains data neither on nonreimbursed nor over-the-counter drugs (eg, low-dose acetylsalicylic acid). According to Finnish reimbursement rules, drugs can be reimbursed for a maximum of 3 months supply at one dispensing. ${ }^{26}$ The Special Reimbursement Register contains information on entitlements to special reimbursement (either $65 \%$ or $100 \%$ of drug costs in 2015) due to certain severe and chronic diseases. In order to be eligible for special reimbursement, a patient's disease must meet explicit criteria proved by a certificate from a physician. The Hospital Discharge Register contains information on hospital admissions, including inpatient care, day surgeries, and specialized outpatient care in public hospitals. ${ }^{27}$ Data on diagnoses and medical procedures are registered using the International Classification of Diseases (ICD) codes (ICD-10 since 1996) and the Nordic MedicoStatistical Committee classification of surgical procedures.

\section{Warfarin initiators}

Using data from the Prescription Register, we identified persons initiating warfarin therapy between January 1, 2009 and June 30, 2012. We defined initiators as persons who filled a prescription for warfarin during the study period but had not been dispensed warfarin within the previous 365 days. We excluded persons who had been in long-term institutional care any time preceding warfarin initiation and persons with a hospital stay lasting continuously for $>90$ days during the 365 days preceding warfarin initiation in order to confirm that our cohort of initiators did not include persons who may have used warfarin earlier during long-term institutional or hospital care.

\section{Warfarin exposure}

Due to the lack of data on the duration of warfarin prescriptions, we present the rate of bleedings requiring hospitalization for the entire follow-up and separately for the first warfarin episode. To estimate the length of the first warfarin episode, we determined a fixed duration for each warfarin prescription using the waiting time distribution (WTD) method. ${ }^{28}$ Specifically, we identified prevalent warfarin users in 2012, defined as those who had been dispensed warfarin also in 2011, and determined the number of days (since January 1, 2012) in which $80 \%$ of these prevalent users were dispensed warfarin for the first time in 2012. 
Then, we assigned each warfarin prescription a fixed duration obtained this way (111 days). Warfarin episode was deemed to continue until the gap between consecutive dispensations exceeded 111 days. Our WTD estimate was similar for both dose sizes of warfarin (103 days for $3 \mathrm{mg}$ and 115 days for $5 \mathrm{mg}$ ) and robust over time (110-113 days using data from 2009 to 2011). In Finland, warfarin is available in packages of 100 tablets only. To allow for doses less than one tablet per day, periodic dose adjustments, and interruptions in home medication for various reasons, we conducted a sensitivity analysis extending the fixed duration assigned for each prescription to 180 days. ${ }^{11}$ That is, the first warfarin episode was assumed to continue until the gap between consecutive dispensations exceeded 180 days.

\section{Bleeding events}

We determined a bleeding event as an admission to hospital for bleeding. We identified relevant admissions on the basis of primary discharge diagnoses using a list of ICD-10 codes adapted from Gomes et $\mathrm{al}^{11}$ (Table S1). We categorized bleeding events further as intracranial, gastrointestinal, and others. We defined early bleeders as persons with a bleeding event within 30 days of warfarin initiation. The rest of the warfarin initiators were defined as nonearly bleeders, including those with bleeding event later than 30 days of warfarin initiation and those without bleeding event during the follow-up. We defined fatal bleeding events as those where the patient died within 10 days of the hospital admission.

\section{Indications, comorbidities, and medications}

We determined indications, comorbidities, and medications at warfarin initiation date based on data on hospital admissions, special reimbursement codes, and/or dispensed drugs captured from the nationwide health registers (Figure 1). Detailed ICD codes, reimbursement codes, and Anatomical Therapeutic Chemical classification codes are available in Table S1. To describe bleeding risk, we combined data on age, sex, and malignancy. ${ }^{29}$ To define stroke risk (congestive heart failure, hypertension, age $\geq 75$, diabetes and stroke $\left[\mathrm{CHADS}_{2}\right]$, reflects stroke risk in patients with atrial fibrillation not receiving anticoagulant therapy), we combined data on heart failure, hypertension, age $\geq 75$ years, diabetes, and ischemic stroke/transient ischemic attack. ${ }^{30}$ We determined Charlson comorbidity index by identifying 17 comorbidities based on hospital admissions over a 1 -year period preceding the warfarin initiation date. ${ }^{31}$

\section{Interacting drugs}

We determined exposure to interacting drugs at warfarin initiation date (Figure 1). A person was considered as exposed if interacting drug prescription overlapped with the warfarin initiation date or was filled at the warfarin initiation

$\begin{array}{ll}\text { Indications }^{\mathbf{a}} & \begin{array}{l}\text { Hospital admission } \\ \text { Special reimbursement }\end{array} \\ \text { Comorbidities }^{\mathrm{b}} & \text { Hospital admission } \\ & \text { Special reimbursement } \\ & \text { Prescription dispensed } \\ \text { Medications }^{\mathrm{c}} & \text { Prescription dispensed } \\ \text { Interacting drugs }^{\mathrm{d}} & \text { Prescription overlap }\end{array}$

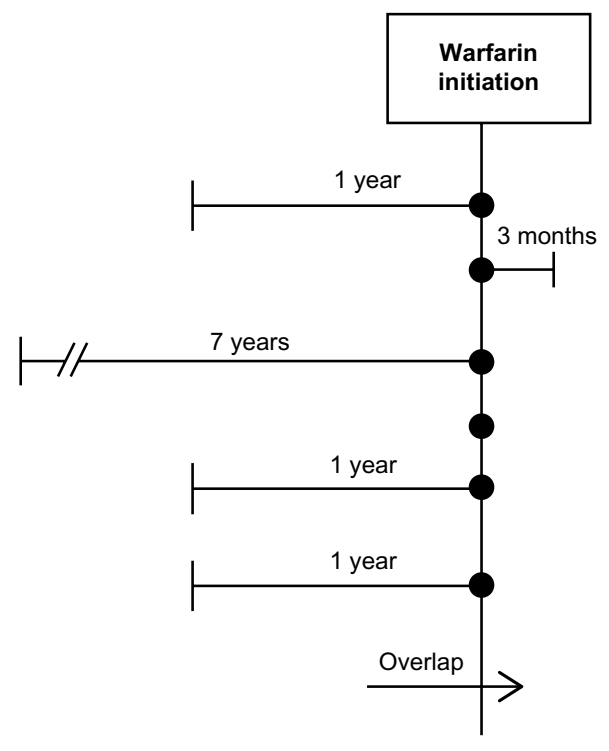

Figure I Measurement of indications, comorbidities, medications, and exposure to interacting drugs.

Notes: a hospital admission within a I-year period before or at the warfarin initiation date, or a valid entitlement to special reimbursement at the warfarin initiation date, or within a 3-month period after the warfarin initiation date. ${ }^{\mathrm{b}} \mathrm{A}$ hospital admission within a 7-year period before or at the warfarin initiation date, or a valid entitlement to special reimbursement at the warfarin initiation date, or a prescription dispensed within a I-year period before or at the warfarin initiation date. ${ }^{\mathrm{A}} \mathrm{A}$ prescription dispensed within a I-year period before or at the warfarin initiation date. ${ }^{\mathrm{d}} \mathrm{A}$ prescription overlapped with the warfarin initiation date, or a prescription dispensed at the warfarin initiation date. 
date. We identified drugs having potential for clinically significant interaction with warfarin from the Swedish, Finnish, Interaction X-referencing drug-drug interaction database. ${ }^{32}$ We defined the duration of each interacting drug prescription (except those for antimicrobials) based on the quantity dispensed, assuming a dosage equal to one defined daily dose per day. ${ }^{25}$ However, we truncated the duration to 100 days, that is, the maximum duration of treatment reimbursed at one dispensing. ${ }^{26}$ Finally, we multiplied the duration by 1.5 to allow for nonadherence. We defined the duration of each prescription for antimicrobials as 7 days.

\section{Analyses}

We calculated the rate of bleeding events for the entire follow-up by dividing the number of persons with a bleeding event by the sum of PYs of follow-up. The follow-up started from the warfarin initiation and lasted until the first bleeding event, death, or administrative end of the study (December 31, 2012), whichever occurred first. The rate of bleeding events for the first 14-day period and for each 30-day period (months) starting from warfarin initiation was calculated among those alive at the beginning of the period and without bleeding event in the previous periods. In the site-specific analyses of bleeding rate (intracranial, gastrointestinal, and other), bleeding events in other sites did not cause censoring of follow-up. In addition, we calculated the rate of bleeding events during the first warfarin episode; the follow-up started from the warfarin initiation date and lasted until the end of the first warfarin episode, the first bleeding event, long-term institutional care, or $>90$-day admission to hospital, death, or administrative end of the study, whichever occurred first.

We characterized early bleeders and nonearly bleeders by known and potential risk factors for bleeding measured by the register data at warfarin initiation, including age, sex, indication for warfarin therapy, bleeding history, comorbidities, medications, Charlson comorbidity index, bleeding risk score, $\mathrm{CHADS}_{2}$ score, and exposure to interacting drugs.

In addition, we performed age-adjusted and multivariableadjusted Cox proportional hazards regression analyses to determine characteristics associated with an early bleeding event, expressing the results as hazard ratios (HRs) and their 95\% confidence intervals (CIs). The potential predictors were age, sex, indications for warfarin therapy, history of any bleeding requiring hospitalization $<180$ days before and during 180 days -7 years before warfarin initiation, individual comorbidities, Charlson comorbidity index, number of drugs in use during the year preceding warfarin initiation, and expo- sure to interacting drugs at warfarin initiation. The results of the multivariable analyses are presented with and without adjustment for the Charlson comorbidity index (as this index includes many of the separately measured disease states) and the number of drugs (as the number of drugs is also a measure of overall morbidity). The bleeding risk and $\mathrm{CHADS}_{2}$ scores are combinations of age and other variables already in the model; therefore, these scores were excluded from the ageadjusted and multivariable-adjusted analyses.

The proportional hazards assumption was checked both graphically and by testing the significance of the interaction term between the predictor and logarithmic time. The assumption was found to be reasonably fulfilled except for the variable history of any bleeding requiring hospitalization $<180$ days before warfarin initiation. This variable was included in the multivariable Cox proportional hazards models as a stratifying variable. In addition, we performed multicollinearity diagnostics for all the predictors included in the multivariable Cox models; we did not observe any sign of strong multicollinearity as the values of the variance inflation factor were $<5$ for all predictors.

\section{Ethical issues}

This study was institutionally approved by SII and THL. As the research team received only deidentified data and the patients were not contacted, consent was neither required by SII or THL, nor sought by the authors.

\section{Results}

A total of 102,048 persons initiated warfarin therapy between January 1, 2009 and June 30, 2012. We excluded 460 persons as they had been in long-term institutional care before warfarin initiation or were continuously hospitalized for $>90$ days during the preceding year. Finally, our study population consisted of 101,588 warfarin initiators.

\section{Rate of bleeding events}

Of warfarin initiators, 5,354 were hospitalized for a bleeding during the entire follow-up of 204,592 PYs (median 1.9 years, interquartile range [IQR]: 1.1-2.9 years), resulting in a rate of $2.6 \%$ per PY (Table 1). The rate was the highest early after warfarin initiation, being $7.9 \%$ per PY (95\% CI 7.05\%-8.8\%) for the first 14 days and 6.5\% per PY (95\% CI 6.0\%-7.1\%) for the first 30 days. After the first 12 months, the rate stabilized $\sim 2 \%$ per PY (Figure 2 ). Among warfarin initiators, $81.7 \%(\mathrm{n}=83,046)$ discontinued therapy during the follow-up and half of them $(n=43,750)$ after the first warfarin prescription. The median duration of the first 
Table I Rate of bleedings requiring hospitalization (\% per PY) among warfarin initiators during the first 30 days after initiation and during the entire follow-up $(n=101,588)$

\begin{tabular}{llllll}
\hline Bleeding site & \multicolumn{2}{l}{ First 30 days } & & \multicolumn{2}{l}{ Entire follow-up } \\
\cline { 2 - 3 } \cline { 5 - 6 } & Number of bleeders & Rate, \% per PY $\mathbf{( 9 5 \% ~ C l )}$ & & Number of bleeders & Rate, \% per PY (95\% Cl) \\
\hline Any bleeding & 539 & $6.5(6.0-7.1)$ & 5,354 & $2.6(2.5-2.7)$ \\
Intracranial bleeding & 83 & $1.0(0.8-1.2)$ & 920 & $0.4(0.4-0.5)$ \\
Gastrointestinal bleeding & 192 & $2.3(2.0-2.7)$ & & 1,874 & $0.9(0.9-0.9)$ \\
Other bleeding & 267 & $3.2(2.8-3.6)$ & 2,721 & $1.3(1.3-1.4)$ \\
\hline
\end{tabular}

Abbreviations: $\mathrm{Cl}$, confidence interval; PY, person-year.

warfarin episode was 5.5 months (IQR: 3.7-9.5 months). The number of initiators with a bleeding event during the first warfarin episode (altogether 69,656 PYs) was 2,283 , resulting in a rate of $3.3 \%$ per PY (95\% CI 3.1-3.4). When the first warfarin episode was assumed to continue until the gap between consecutive prescriptions exceeded 180 days (instead of 111 days), the median duration of the episode was 10.6 months (IQR: 6-20.1 months) and the rate of any bleeding requiring hospitalization was 3.0\% per PY (95\% CI 2.9-3.1). Figure S1 shows the rate of bleeding events during the first warfarin episode on the assumptions of prescription duration of 111 and 180 days.

The rate of bleeding events during the entire follow-up was similar across indications (from $2.9 \%$ to $3.1 \%$ per PY), with the exception of lower rate among those with venous thrombosis (2.1\% per PY, 95\% CI 2.0-2.3). The rate of bleeding events within the first 30 days of warfarin initiation was the highest among those with pulmonary embolism (10.9\% per PY 95\% CI 8.4\%-13.9\%) or venous thrombosis (10.2\% per PY, 95\% CI 8.3\%-12.5\%).

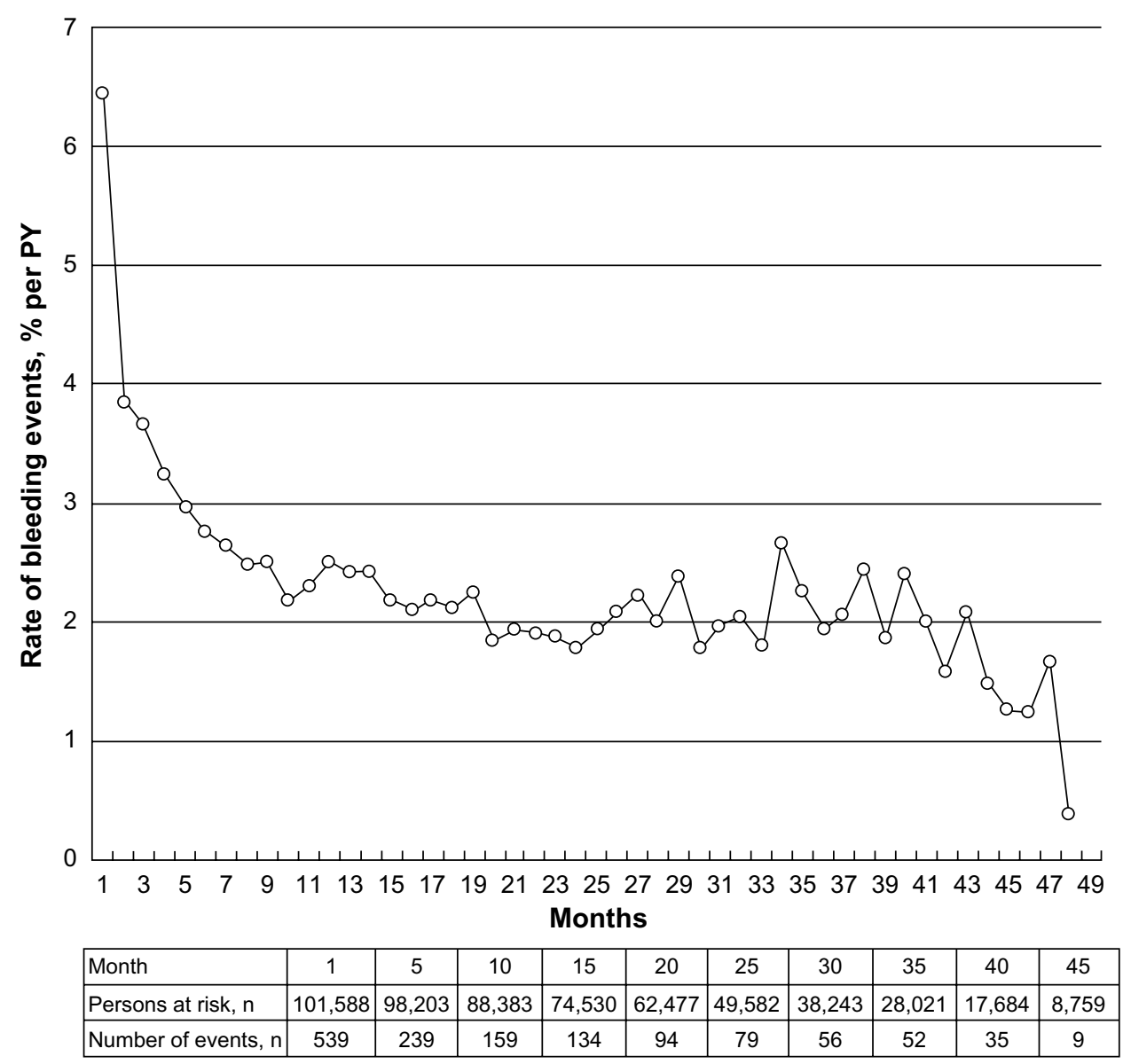

Figure 2 Rate of bleedings requiring hospitalization during the entire follow-up for each month starting from warfarin initiation (n=I0I,588). Abbreviation: PY, person-year. 
The distribution of bleeding site was similar among all 5,354 bleeding events and among 539 early bleeding events, with $16 \%$ of bleeding events being intracranial, $\sim 35 \%$ gastrointestinal, and $\sim 49 \%$ other bleedings. Overall, $5.3 \%$ $(n=283)$ of all bleeding events (200 of intracranial, 68 of gastrointestinal, and 15 of other bleeding events) and 2.6\% $(n=14)$ of early bleeding events were fatal (eight of intracranial, five of gastrointestinal, and one of other bleedings).

\section{Characteristics of early bleeders}

Among 539 early bleeders, $74.0 \%$ were $\geq 65$ years and $56.4 \%$ were men. Nonearly bleeders were younger and less frequently men than early bleeders (Table 2 ). Approximately $40 \%$ of both early bleeders and nonearly bleeders had atrial fibrillation. One-third of early bleeders (31.0\%) and less than one-tenth of nonearly bleeders (7.4\%) had a history of bleeding. Most of the addressed comorbidities and medications were more common among early bleeders than among nonearly bleeders. In addition, early bleeders were more frequently exposed to interacting drugs (67.5\%) than nonearly bleeders (57.1\%) (Table 3 ). The hazard of early bleeding did not increase consistently with an increasing value of the bleeding risk score (Table 2). Among those identified as patients with atrial fibrillation, a CHADS 2 score $>2$ predicted an $87 \%$ increase in the hazard of early bleeding.

Based on multivariable Cox proportional hazards regression analysis, those with a history of bleeding were most likely to experience an early bleeding (Table 4). The HR for early bleeding associated with the history of bleeding during 180 days -7 years before warfarin initiation variable was 1.48 (95\% CI 1.15-1.91). When history of bleeding within $<180$ days prior to initiation was not treated as a stratifying variable, its (average) HR was 13.7 (95\% CI 10.9-17.1). In addition, early bleeders were characterized by older age (HR $=1.13,95 \%$ CI $1.04-1.22$, per 10-year increase in age), male sex ( $\mathrm{HR}=1.32,95 \%$ CI 1.10-1.57), venous thrombosis ( $\mathrm{HR}=1.83,95 \%$ CI $1.44-2.34)$, pulmonary embolism (HR $=1.46,95 \%$ CI 1.11-1.91), alcohol abuse (HR $=1.59,95 \%$ CI 1.08-2.35), rheumatic disease ( $\mathrm{HR}=1.40,95 \% \mathrm{CI} 1.07-1.83)$, and exposure to drugs with dynamic mechanism of interaction with warfarin $(\mathrm{HR}=1.43$, 95\% CI 1.20-1.71). When the model was further adjusted for Charlson comorbidity index and the number of drugs in use during the past year, the preceding associations were slightly attenuated and the HR for rheumatic disease was not significant any more. In age-adjusted models, Charlson comorbidity index and number of drugs predicted a steep graded increase in the hazard of early bleeding; these associations were attenuated when adjusted for other predictors.

\section{Discussion}

In this population-based cohort study, we found that the rate of bleeding leading to hospitalization was $2.6 \%$ per PY among noninstitutionalized Finnish persons initiating warfarin therapy over a median of 1.9 years of follow-up. The rate of bleeding requiring hospitalization peaked within the first month of warfarin initiation ( $6.5 \%$ per PY), especially among those with pulmonary embolism or venous thrombosis. One-third of early bleeders had a history of bleeding. Besides being characterized by prior bleeding, pulmonary embolism, or venous thrombosis, early bleeders were older, male, had history of alcohol abuse or rheumatic disease, and were using drugs with pharmacodynamic interaction mechanism with warfarin.

The rate of bleeding hospitalizations was higher during the first warfarin episode $(3.0 \%-3.3 \%$ per PY) than during the entire follow-up (2.6\% per PY). This may result from the fact that $\sim 40 \%$ of the initiators discontinued therapy after the first prescription, and therefore, the first warfarin episode emphasized the beginning of therapy when the rate of bleeding was the highest. In addition, the difference may arise from the fact that the entire follow-up included persontime after warfarin discontinuation. However, the incidence of bleeding may not decrease immediately after the end of warfarin therapy since factors leading to discontinuation may be related to the appearance of early signs of bleeding. One previous study showed a minor increase in the bleeding incidence during the first month after warfarin discontinuation, but a decrease thereafter. ${ }^{10}$

Our estimates on the rate of bleeding among warfarin initiators fall within the range of $1.9 \%-7.6 \%$ per PY, which was reported previously by observational studies among patients with atrial fibrillation receiving warfarin therapy. ${ }^{4,7-16}$ Differences in the rates between the studies may largely emerge due to differences in the definitions of bleeding, the age distribution of the study populations, and the length of follow-up (as the incidence peaks in the beginning of warfarin therapy). Moreover, many studies have not excluded persons with prior warfarin exposure, resulting in the underestimation of early events. In our study, the rate of bleeding among those with verified atrial fibrillation was $2.9 \%$ per PY during the first warfarin episode (data not shown), being somewhat smaller than that (3.8\% per PY) reported in a Canadian study with a similar definition for bleeding events among patients with 
Table 2 Characteristics of early bleeders $(n=539)$ and nonearly bleeders $(n=101,049)$ at the warfarin initiation date

\begin{tabular}{|c|c|c|c|}
\hline Characteristics & Early bleeders & Nonearly bleeders & Unadjusted HR (95\% Cl) \\
\hline \multicolumn{4}{|l|}{ Demographics } \\
\hline Men & $56.4(304)$ & $51.5(52,018)$ & $1.22(1.03-1.45)$ \\
\hline Age, years, median (IQR) & $73(64-8 I)$ & $72(62-80)$ & $1.10(1.03-1.17)^{\mathrm{a}}$ \\
\hline$\leq 64$ & $26.0(140)$ & $30.8(3 I, 08 I)$ & 1.00 (reference) \\
\hline $65-74$ & $27.5(148)$ & $26.5(26,799)$ & $1.23(0.97-1.54)$ \\
\hline$\geq 75$ & $46.6(25 I)$ & $42.7(43,169)$ & $1.29(1.05-1.59)$ \\
\hline \multicolumn{4}{|l|}{ Indications } \\
\hline Atrial fibrillation & $37.9(204)$ & $40.1(40,560)$ & $0.91(0.76-1.08)$ \\
\hline Venous thrombosis & $17.6(95)$ & II.2(II,272) & $1.70(1.36-2.12)$ \\
\hline Mechanical heart valve & $12.1(65)$ & $12.0(12,144)$ & $1.00(0.78-1.30)$ \\
\hline Pulmonary embolism & $12.2(66)$ & $7.3(7,357)$ & $1.78(1.37-2.30)$ \\
\hline Ischemic stroke or transient ischemic attack & II.5 (62) & $8.9(8,985)$ & $1.33(1.02-1.73)$ \\
\hline \multicolumn{4}{|l|}{ History of bleeding } \\
\hline Any bleeding & $31.0(167)$ & $7.4(7,523)$ & $5.53(4.6 \mathrm{I}-6.64)$ \\
\hline I day- $<\mid 80$ days before warfarin initiation & $20.0(108)$ & $1.3(1,345)$ & $17.9(14.5-22.2)$ \\
\hline 180 days -7 years before warfarin initiation & $14.3(77)$ & $6.4(6,490)$ & $2.42(1.90-3.08)$ \\
\hline Intracranial bleeding & $6.7(36)$ & $0.7(663)$ & $10.6(7.57-14.9)$ \\
\hline Gastrointestinal bleeding & $8.9(48)$ & $2.9(2,933)$ & $3.25(2.42-4.38)$ \\
\hline Other bleeding & I7.I (92) & $4.2(4,207)$ & $4.70(3.75-5.88)$ \\
\hline \multicolumn{4}{|l|}{ Comorbidities } \\
\hline Coronary artery disease & $45.8(247)$ & $43.0(43,445)$ & $1.12(0.95-1.33)$ \\
\hline Heart failure & $19.3(104)$ & $17.0(17,179)$ & $1.17(0.95-1.45)$ \\
\hline Ischemic stroke or transient ischemic attack & $17.3(93)$ & I4.I $(14,260)$ & $1.27(1.01-1.59)$ \\
\hline Hypertension & $51.6(278)$ & $46.3(46,782)$ & $1.24(1.04-1.46)$ \\
\hline Peripheral arterial disease & $6.3(34)$ & $4.6(4,657)$ & $1.40(0.99-1.98)$ \\
\hline Thrombosis in cerebral arteries or in intracranial veins & I.I (6) & $1.2(I, 190)$ & $0.95(0.42-2.11)$ \\
\hline Diabetes & $18.6(100)$ & $18.2(|8,43|)$ & $1.02(0.82-1.27)$ \\
\hline Renal impairment & $4.6(25)$ & $2.5(2,497)$ & $1.92(1.29-2.87)$ \\
\hline Liver disease & $2.2(12)$ & $1.0(1,047)$ & $2.17(1.23-3.85)$ \\
\hline Dementia & $4.8(26)$ & $4.6(4,691)$ & $1.05(0.7 \mathrm{I}-1.55)$ \\
\hline Malignancy & $17.4(94)$ & $13.6(13,742)$ & $1.34(1.08-1.68)$ \\
\hline Alcohol abuse & $5.8(31)$ & $3.0(3,009)$ & $1.98(1.38-2.85)$ \\
\hline Pulmonary disease & $18.9(102)$ & $16.0(16,121)$ & $1.23(0.99-1.53)$ \\
\hline Rheumatic disease & $11.7(63)$ & $7.1(7,122)$ & $1.74(1.34-2.27)$ \\
\hline Gastrointestinal disease & $42.3(228)$ & $31.3(3|, 6| 2)$ & $1.61(1.36-1.91)$ \\
\hline Charlson comorbidity index, median (IQR) & I (0-2) & $0(0-1)$ & $1.27(1.19-1.36)$ \\
\hline \multicolumn{4}{|l|}{ Medications } \\
\hline Number of drugs, median (IQR) & $10(7-14)$ & $9(6-12)$ & $1.82(1.55-2.13)^{\mathrm{b}}$ \\
\hline Any cardiovascular drug & $86.3(465)$ & $85.0(85,908)$ & I.II (0.87-I.42) \\
\hline Antithrombotic drugs & $40.5(218)$ & $26.9(27,180)$ & $1.84(1.55-2.19)$ \\
\hline Lipid-modifying drugs & $44.5(240)$ & $43.2(43,697)$ & $1.05(0.89-1.25)$ \\
\hline \multicolumn{4}{|l|}{ Bleeding risk score ${ }^{c}$} \\
\hline 0 & II.3 (6I) & I3.4 (I3,497) & 1.00 (reference) \\
\hline $1.3-1.6$ & $40.3(217)$ & $38.5(38,865)$ & $1.24(0.93-1.64)$ \\
\hline $2.2-2.9$ & $32.1(173)$ & $35.1(35,503)$ & $\mathrm{I} .08(0.8 \mathrm{I}-\mathrm{I} .45)$ \\
\hline$\geq 3.5$ & $16.3(88)$ & $13.0(13,184)$ & $1.48(1.07-2.05)$ \\
\hline \multicolumn{4}{|l|}{$\mathrm{CHADS}_{2}$ score $^{\mathrm{d}}$ (among those with atrial fibrillation, $\mathrm{n}=40,764$ ) } \\
\hline 0 & $11.8(24)$ & $18.9(7,662)$ & 1.00 (reference) \\
\hline I & $26.0(53)$ & $27.6(11,191)$ & $1.5 \mathrm{I}(0.93-2.45)$ \\
\hline 2 & $30.4(62)$ & $26.1(10,577)$ & $1.87(1.17-3.00)$ \\
\hline$\geq 3$ & $31.9(65)$ & $27.4(11,130)$ & $1.87(1.17-2.98)$ \\
\hline
\end{tabular}

Notes: Data shown as percentage (n), median (IQR), or unadjusted HR (95 \% Cl). HRs reported for presence versus absence of a characteristic unless otherwise stated. ${ }^{a}$ Per 10 years. ${ }^{b}$ Per one unit increase in the number of drugs measured on a logarithmic scale. 'Bleeding risk score defined based on age, sex, and malignancy, and ranges from 0 to $5.1 .{ }^{32}{ }^{\mathrm{d}} \mathrm{CHADS}_{2}$ score reflects the risk of stroke in persons with atrial fibrillation, defined based on heart failure, hypertension, age $\geq 75$ years, diabetes, stroke/transient ischemic attack, and ranges from 0 to $6 .^{33}$

Abbreviations: $\mathrm{CHADS}_{2}$, congestive heart failure, hypertension, age $\geq 75$, diabetes and stroke; $\mathrm{Cl}$, confidence interval; $\mathrm{HR}$, hazard ratio; IQR, interquartile range. 
Table 3 Exposure to interacting drugs at the warfarin initiation date among early bleeders $(n=539)$ and nonearly bleeders $(n=\mid 01,049)$

\begin{tabular}{|c|c|c|}
\hline Interacting drugs & $\begin{array}{l}\text { Early } \\
\text { bleeders, \% (n) }\end{array}$ & $\begin{array}{l}\text { Nonearly } \\
\text { bleeders, \% (n) }\end{array}$ \\
\hline Any interacting drug & $67.5(364)$ & $57.1(57,731)$ \\
\hline One interacting drug & $37.9(204)$ & $35.5(35,902)$ \\
\hline Two interacting drugs & $21.0(113)$ & $15.8(15,958)$ \\
\hline Three or more interacting drugs & $8.7(47)$ & $5.8(5,87 I)$ \\
\hline $\begin{array}{l}\text { Any drug with dynamic } \\
\text { mechanism of interaction }\end{array}$ & $53.3(287)$ & $4 I . I(4 I, 493)$ \\
\hline Paracetamol & $26.2(14 \mid)$ & $19.4(19,574)$ \\
\hline Prednisolone & $9.1(49)$ & $5.9(5,907)$ \\
\hline Levothyroxine & $7.6(4 I)$ & $6.8(6,863)$ \\
\hline Clopidogrel & $5.8(3 \mathrm{I})$ & $3.2(3,278)$ \\
\hline Ibuprofen & $5.6(30)$ & $5.3(5,3 \mid 0)$ \\
\hline Citalopram & $3.5(19)$ & $2.5(2,546)$ \\
\hline Etoricoxib & $3.0(16)$ & I.5 $(I, 497)$ \\
\hline Escitalopram & $2.6(14)$ & $1.6(1,627)$ \\
\hline Tramadol & $2.4(13)$ & $2.1(2,166)$ \\
\hline Diclofenac & I.3 (7) & I.3 $(1,348)$ \\
\hline Naproxen & $0.7(4)$ & $1.0(1,023)$ \\
\hline Dexamethasone & I.3 (7) & $0.4(356)$ \\
\hline Methylprednisolone & $\mathrm{I} .5(8)$ & $0.5(503)$ \\
\hline Meloxicam & $0.9(5)$ & $0.8(837)$ \\
\hline Venlafaxine & $0.6(3)$ & $0.6(610)$ \\
\hline $\begin{array}{l}\text { Any drug with kinetic } \\
\text { mechanism of interaction }\end{array}$ & $3.3(18)$ & $3.3(3,299)$ \\
\hline Amiodarone & $0.9(5)$ & $1.0(1,0 \mid 4)$ \\
\hline Fluvastatin & $0.7(4)$ & I.4 (I,377) \\
\hline $\begin{array}{l}\text { Any drug with unclear } \\
\text { mechanism of interaction }\end{array}$ & $27.1(146)$ & $24.8(25,055)$ \\
\hline Simvastatin & $24.5(132)$ & $22.9(23,180)$ \\
\hline Rosuvastatin & $2.2(12)$ & $2.0(2,003)$ \\
\hline Ciprofloxacin & $0.9(5)$ & $0.6(586)$ \\
\hline Levofloxacin & I.3 (7) & $0.6(607)$ \\
\hline Doxycycline & $0.6(3)$ & $0.7(652)$ \\
\hline
\end{tabular}

Notes: Persons were considered as exposed if interacting drug prescription overlapped with the warfarin initiation date. Individual drugs with a prevalence of $<0.5 \%$ in both early and nonearly bleeders are excluded.

atrial fibrillation during their first warfarin episode. ${ }^{11}$ We used a stricter definition for a bleeding event (identified based on primary discharge diagnoses only) and our study population was younger, which may explain the difference in the rates.

The peak in the bleeding rate in the beginning of warfarin therapy may arise from difficulty to achieve the target INR. ${ }^{18}$ However, in the absence of data on INR values, we were unable to assess whether early bleedings occurred at INR above the therapeutic range. In Finland, persons on warfarin therapy have been reported to spend on an average $\sim 13 \%$ of the time above the therapeutic range, ${ }^{33,34}$ but there are no data whether this proportion is higher in the beginning of therapy. In a British study, time spent above the therapeutic range was $20 \%$ in the first month after warfarin initiation and $\sim 15 \%$ in the following 2 years, ${ }^{35}$ suggesting that the time spent above the therapeutic range varies modestly across the duration of therapy.

The early peak in the rate of bleeding may further result from the early attrition of those most susceptible to bleeding. ${ }^{18}$ We found that early bleeders were characterized by prior bleeding, older age, history of alcohol abuse, and exposure to drugs with pharmacodynamic interaction mechanism with warfarin, all of which increase the bleeding risk without affecting the INR. Therefore, the initiation of warfarin therapy in the presence of these characteristics requires particular consideration and monitoring, as well as careful evaluation of prior medication. Unfortunately, we could not evaluate the exposure to low-dose acetylsalicylic acid, the use of which is common among warfarin initiators ${ }^{13}$ and has been associated with an increased bleeding risk during warfarin therapy. ${ }^{12,36,37}$ In addition, it should be noted that early bleeders may have suffered from undiagnosed and untreated comorbidities, such as peptic ulcer or malignancy, that have predisposed them to bleeding.

The peak in the rate of bleeding during the first month after warfarin initiation was most prominent among persons with pulmonary embolism (10.9\% per PY) or venous thrombosis (10.2\% per PY). We do not have an explicit explanation for our observation, but it could be related to the fact that those with pulmonary embolism or venous thrombosis were more frequently exposed to nonsteroidal anti-inflammatory drugs (NSAIDs) at warfarin initiation (13.1\% and $18.3 \%$, respectively) than those receiving warfarin for other indications $(7.2 \%-8.9 \%)$; however, when we added NSAID use at warfarin initiation to our multivariable model, the HRs for venous thrombosis or pulmonary embolism did not change (data not shown). In addition, those with pulmonary embolism or venous thrombosis may have been exposed to higher warfarin doses, an important risk factor for bleeding. ${ }^{38}$ Nonetheless, those with venous thrombosis and pulmonary embolism had higher rates of bleeding events only in the beginning of warfarin therapy, not during the entire follow-up. This accords with previous studies not illustrating a higher incidence of bleeding among those with venous thrombosis compared with other indications. ${ }^{4,39}$

Early bleedings were further predicted by rheumatic disease. Persons with rheumatic disease were commonly exposed to corticosteroids (29.2\%) and NSAIDs $(17.8 \%)$ at warfarin initiation; however, the inclusion of the use of NSAIDs in the multivariable model did not affect the HR for early bleeding associated with rheumatic disease. 
Table 4 Factors associated with early bleeding among warfarin initiators $(n=101,588)$

\begin{tabular}{|c|c|c|c|}
\hline Factors & $\begin{array}{l}\text { Age-adjusted HR } \\
(95 \% \mathrm{Cl})\end{array}$ & $\begin{array}{l}\text { Multivariable-adjusted } \\
\text { HR }(95 \% \mathrm{Cl})^{\mathrm{a}}\end{array}$ & $\begin{array}{l}\text { Multivariable-adjusted } \\
\text { HR }(95 \% \mathrm{CI})^{\mathrm{b}}\end{array}$ \\
\hline \multicolumn{4}{|l|}{ Sex } \\
\hline Men & $1.30(1.09-1.55)$ & $1.32(1.10-1.57)$ & $1.34(1.11-1.60)$ \\
\hline \multicolumn{4}{|l|}{ Age } \\
\hline Per 10 years & NA & $1.13(1.04-1.22)$ & $1.12(1.04-1.21)$ \\
\hline \multicolumn{4}{|l|}{ Indications } \\
\hline Atrial fibrillation & $0.87(0.73-1.03)$ & $\mathrm{I} .00(0.83-1.2 \mathrm{I})$ & $0.98(0.81-1.19)$ \\
\hline Venous thrombosis & $1.94(1.54-2.44)$ & $1.83(1.44-2.34)$ & $1.80(I .4 I-2.92)$ \\
\hline Mechanical heart valve & $1.04(0.80-1.34)$ & $0.99(0.76-1.30)$ & $0.95(0.73-1.24)$ \\
\hline Pulmonary embolism & $1.85(1.43-2.40)$ & $1.46(1.11-1.91)$ & $1.42(1.09-1.87)$ \\
\hline Ischemic stroke or transient ischemic attack & $1.31(I .0 I-1.7 I)$ & $\mathrm{I} .22(0.93-1.6 \mathrm{I})$ & $1.04(0.77-1.39)$ \\
\hline \multicolumn{4}{|l|}{ History of bleeding } \\
\hline During I day $-<180$ days before warfarin initiation & $17.7(|4.3-2| .9)$ & NA & NA \\
\hline During 180 days -7 years before warfarin initiation & $2.35(1.84-2.99)$ & $1.48(1.15-1.90)$ & $1.46(1.14-1.88)$ \\
\hline \multicolumn{4}{|l|}{ Comorbidities } \\
\hline Coronary artery disease & $1.04(0.87-1.24)$ & $1.00(0.82-1.21)$ & $0.95(0.78-1.15)$ \\
\hline Heart failure & $1.10(0.88-1.37)$ & $\mathrm{I} .04(0.83-\mid .3 \mathrm{I})$ & $0.93(0.73-1.18)$ \\
\hline Hypertension & $1.17(0.98-1.39)$ & $1.13(0.94-1.35)$ & $1.07(0.89-1.29)$ \\
\hline Peripheral arterial disease & $1.34(0.94-1.90)$ & I.II (0.78-I.59) & $1.04(0.73-1.49)$ \\
\hline Thrombosis in cerebral arteries or in intracranial veins & $0.97(0.43-2.16)$ & $0.75(0.33-1.68)$ & $0.72(0.32-1.62)$ \\
\hline Diabetes & $0.99(0.80-1.24)$ & $0.88(0.70-1.10)$ & $0.79(0.63-1.01)$ \\
\hline Renal impairment & $1.87(1.25-2.79)$ & $1.22(0.8 \mathrm{I}-1.85)$ & $1.09(0.71-1.67)$ \\
\hline Liver disease & $2.27(1.28-4.02)$ & $1.40(0.77-2.56)$ & $1.29(0.7 \mathrm{I}-2.36)$ \\
\hline Dementia & $0.92(0.62-1.38)$ & $0.89(0.60-1.34)$ & $0.82(0.55-1.23)$ \\
\hline Malignancy & $1.28(1.02-1.60)$ & $1.06(0.85-1.34)$ & $0.94(0.74-1.20)$ \\
\hline Alcohol abuse & $2.18(1.51-3.15)$ & $1.59(1.08-2.35)$ & $1.55(1.05-2.28)$ \\
\hline Pulmonary disease & $1.21(0.97-1.50)$ & $\mathrm{I} .05(0.84-\mid .3 \mathrm{I})$ & $0.95(0.75-1.19)$ \\
\hline Rheumatic disease & $1.70(1.31-2.21)$ & $1.40(1.07-1.83)$ & $1.30(0.99-1.71)$ \\
\hline Gastrointestinal disease & $1.58(1.33-1.87)$ & $1.10(0.92-1.33)$ & $1.02(0.84-1.24)$ \\
\hline \multicolumn{4}{|l|}{ Charlson comorbidity index } \\
\hline 0 & 1.00 & NA & 1.00 \\
\hline $1-3$ & $1.74(1.46-2.07)$ & NA & $1.32(1.06-1.65)$ \\
\hline $4-9$ & $3.14(2.08-4.74)$ & NA & $1.66(0.99-2.76)$ \\
\hline \multicolumn{4}{|l|}{ Number of drugs } \\
\hline $1-4$ & 1.00 & NA & 1.00 \\
\hline $5-9$ & $1.82(1.30-2.55)$ & NA & $1.56(1.10-2.20)$ \\
\hline $10-14$ & $2.16(1.53-3.06)$ & NA & $1.57(I .06-2.31)$ \\
\hline$\geq 15$ & $3.14(2.20-4.50)$ & NA & $1.88(1.20-2.93)$ \\
\hline \multicolumn{4}{|l|}{ Exposure to interacting drugs } \\
\hline Drugs with dynamic mechanism of interaction & $1.63(1.38-1.93)$ & I.43 (I.20-|.7I) & $1.32(1.10-1.59)$ \\
\hline Drugs with kinetic mechanism of interaction & $1.01(0.63-1.61)$ & $0.94(0.59-1.52)$ & $0.90(0.56-1.44)$ \\
\hline Drugs with unclear mechanism of interaction & $1.10(0.91-1.34)$ & $1.10(0.90-1.33)$ & $1.05(1.05-2.28)$ \\
\hline
\end{tabular}

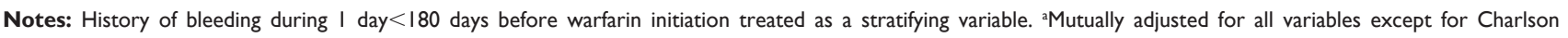
comorbidity index and number of drugs; ${ }^{b}$ mutually adjusted for all variables.

Abbreviations: $\mathrm{Cl}$, confidence interval; HR, hazard ratio; NA, not applicable.

In our study, the proportion of fatal bleedings was lower $(5.3 \%)$ than those observed in previous studies $(7.2 \%-18.1 \%){ }^{10,11}$ This was evident for the proportion of fatal intracranial bleedings as well $(21.6 \%$ vs $\sim 40 \%),{ }^{10,11}$ suggesting that the lower proportion was not due to inclusion of less severe bleedings. The lower proportion was also not due to younger study population since the proportion of fatal bleedings increased only modestly (6.1\%) when those aged $<65$ years were excluded. Furthermore, the lower proportion is not likely to be explained by our approach to include all indications since indication for warfarin therapy appears to have a limited impact on fatality of bleeding. ${ }^{39}$

\section{Methodological considerations}

The strengths of our study include a large study sample representative to noninstitutionalized Finnish population, up-to-date data, and comprehensive data sources. In addition, 
by following initiators, instead of prevalent warfarin users, we were able to detect the early peak in the rate of bleeding. In addition, our data are from the time before non-vitamin $\mathrm{K}$ antagonist oral anticoagulants became reimbursable among patients with atrial fibrillation, pulmonary embolism, or venous thrombosis, ${ }^{40}$ and therefore, our cohort represents the whole range of oral anticoagulant initiators.

Some limitations need to be noted. First, we did not have data on minor bleedings that did not result in hospital admission or fatal bleedings leading to death without hospital admission, resulting in underestimation of the rate of bleeding events. Second, there are no validation studies dealing with the quality of the Hospital Discharge Register for bleeding events except for intracranial hemorrhage. Overall, the completeness and accuracy of this register have been shown to be at least satisfactory and good in case of intracranial hemorrhage. ${ }^{24}$ The present study identified bleeding-related hospital admissions with primary ICD-10 codes, which decreases the likelihood of misclassification of patient's prior bleeding as an event. Clinically, it is reasonable to assume that major bleedings are coded accurately. In fact, one Canadian validation study showed that the ICD codes have good sensitivity (93\%), specificity (88\%), and positive predictive (91\%), and negative predictive values (91\%) for the identification of warfarin-related bleedings when compared to medical records. ${ }^{41}$ Third, our data of indications and comorbidities are not complete since they were based on administrative health registers, and we did not have access to primary care registers. ${ }^{42}$ Such misclassification may have diluted the observed associations between comorbidities and the hazard of early bleeding. Fourth, as in any study based on pharmacy dispensation data, we have no way of knowing whether and when the dispensed warfarin was actually consumed. In the absence of data on INR monitoring, we could not assess whether early bleeding events were related to supratherapeutic INR values. As we had no information on the duration of each warfarin prescription, we used a data-driven WTD as a proxy and conducted sensitivity analyses extending the prescription duration to 180 days. The main and sensitivity analyses produced similar results. In addition, we do not know whether the exposure to interacting drugs continued after warfarin initiation. Nevertheless, we previously showed that the interacting drugs are frequently prescribed within the first month of warfarin initiation, ${ }^{43}$ suggesting that warfarin initiation seldom results in the discontinuation of interacting drugs, with the exception of NSAIDs. ${ }^{40}$
Moreover, we may have underestimated exposure to ibuprofen, ketoprofen, and paracetamol as small packages are available over the counter. Finally, exposure to low-dose acetylsalicylic acid (over-the-counter product), alternative medications, dietary factors, smoking, and alcohol was out of reach in our study.

\section{Conclusion}

Our population-based cohort study indicated that the rate of bleeding was the highest in the beginning of warfarin therapy. Persons most susceptible to an early bleeding were characterized by venous thrombosis and pulmonary embolism and factors that increase bleeding risk without alteration in the INR. Therefore, the initiation of warfarin therapy in the presence of these factors requires careful consideration and monitoring.

\section{Acknowledgments}

The work was supported by a grant from the SII of Finland (11/26/2012). Milka Hauta-aho compiled the list of potentially interacting drugs. Arja Helin-Salmivaara served as a scientific advisor for variable definitions.

\section{Disclosure}

The authors report no conflicts of interest in this work.

\section{References}

1. Kirley K, Qato DM, Kornfield R, et al. National trends in oral anticoagulant use in the United States, 2007 to 2011. Circ Cardiovasc Qual Outcomes. 2012;5(5):615-621.

2. Lindh JD, Holm L, Dahl ML, et al. Incidence and predictors of severe bleeding during warfarin treatment. J Thromb Thrombolysis. 2008; 25(2):151-159.

3. Virjo I, Mäkelä K, Aho J, et al. Who receives anticoagulant treatment with warfarin and why? A population-based study in Finland. Scand $J$ Prim Health Care. 2010;28(4):237-241.

4. Wieloch M, Själander A, Frykman V, et al. Anticoagulation control in Sweden: reports of time in therapeutic range, major bleeding, and thrombo-embolic complications from the national quality registry AuriculA. Eur Heart J. 2011;32(18):2282-2289.

5. Go AS, Hylek EM, Chang Y, et al. Anticoagulation therapy for stroke prevention in atrial fibrillation: how well do randomized trials translate into clinical practice? JAMA. 2003;290(20):2685-2692.

6. Hart RG, Pearce LA, Aguilar MI. Meta-analysis: antithrombotic therapy to prevent stroke in patients who have nonvalvular atrial fibrillation. Ann Intern Med. 2007;146(12):857-867.

7. Boulanger L, Hauch O, Friedman M, et al. Warfarin exposure and the risk of thromboembolic and major bleeding events among medicaid patients with atrial fibrillation. Ann Pharmacother. 2006;40(6):1024-1029.

8. Darkow T, Vanderplas AM, Lew KH, et al. Treatment patterns and real-world effectiveness of warfarin in nonvalvular atrial fibrillation within a managed care system. Curr Med Res Opin. 2005;21(10): $1583-1594$.

9. Friberg L, Rosenqvist M, Lip GY. Net clinical benefit of warfarin in patients with atrial fibrillation: a report from the Swedish atrial fibrillation cohort study. Circulation. 2012;125(19):2298-2307. 
10. Gallagher AM, van Staa TP, Murray-Thomas T, et al. Populationbased cohort study of warfarin-treated patients with atrial fibrillation: incidence of cardiovascular and bleeding outcomes. BMJ Open. 2014; 4(1):e003839.

11. Gomes T, Mamdani MM, Holbrook AM, et al. Rates of hemorrhage during warfarin therapy for atrial fibrillation. CMAJ. 2013;185(2): E121-E127.

12. Hansen ML, Sørensen R, Clausen MT, et al. Risk of bleeding with single, dual, or triple therapy with warfarin, aspirin, and clopidogrel in patients with atrial fibrillation. Arch Intern Med. 2010;170(16):1433-1441.

13. Larsen TB, Gorst-Rasmussen A, Rasmussen LH, et al. Bleeding events among new starters and switchers to dabigatran compared with warfarin in atrial fibrillation. Am J Med. 2014;127(7):650-656.

14. Mercaldi CJ, Ciarametaro M, Hahn B, et al. Cost efficiency of anticoagulation with warfarin to prevent stroke in medicare beneficiaries with nonvalvular atrial fibrillation. Stroke. 2011;42(1):112-118.

15. Olesen JB, Lip GY, Hansen PR, et al. Bleeding risk in 'real world' patients with atrial fibrillation: comparison of two established bleeding prediction schemes in a nationwide cohort. J Thromb Haemost. 2011 9(8):1460-1467.

16. Sørensen R, Gislason G, Torp-Pedersen C, et al. Dabigatran use in Danish atrial fibrillation patients in 2011: a nationwide study. BMJ Open. 2013;3(5):e002758.

17. Hylek EM, Evans-Molina C, Shea C, et al. Major hemorrhage and tolerability of warfarin in the first year of therapy among elderly patients with atrial fibrillation. Circulation. 2007;115(21):2689-2696.

18. Garcia DA, Lopes RD, Hylek EM. New-onset atrial fibrillation and warfarin initiation: high risk periods and implications for new antithrombotic drugs. Thromb Haemost. 2010;104(6):1099-1105.

19. Ansell J, Hirsh J, Hylek E, et al; American College of Chest Physicians. Pharmacology and management of the vitamin K antagonists: American college of chest physicians evidence-based clinical practice guidelines (8th Edition). Chest. 2008;133(6 Suppl):160S-198S.

20. Sconce EA, Khan TI, Wynne HA, et al. The impact of CYP2C9 and VKORC1 genetic polymorphism and patient characteristics upon warfarin dose requirements: proposal for a new dosing regimen. Blood. 2005;106(7):2329-2333.

21. Reynolds MW, Fahrbach K, Hauch O, et al. Warfarin anticoagulation and outcomes in patients with atrial fibrillation: a systematic review and metaanalysis. Chest. 2004;126(6):1938-1945.

22. Mearns ES, Kohn CG, Song JS, et al. Meta-analysis to assess the quality of international normalized ratio control and associated outcomes in venous thromboembolism patients. Thromb Res. 2014;134(2): 310-319

23. Oake N, Fergusson DA, Forster AJ, et al. Frequency of adverse events in patients with poor anticoagulation: a meta-analysis. CMAJ. 2007;176(11):1589-1594.

24. Furu K, Wettermark B, Andersen M, et al. The Nordic countries as a cohort for pharmacoepidemiological research. Basic Clin Pharmacol Toxicol. 2010;106(2):86-94.

25. WHO Collaborating Centre for Drug Statistics Methodology. Guidelines for ATC Classification and DDD Assignment, 2013. Oslo: WHO Collaborating Centre for Drug Statistics Methodology; 2014.

26. Finnish Medicines Agency and Social Insurance Institution. Finnish Statistic of Medicine. Helsinki: Finnish Medicines Agency and Social Insurance Institution; 2013.
27. Sund R. Quality of the Finnish Hospital Discharge Register: a systematic review. Scand J Public Health. 2012;40(6):505-515.

28. Pottegård A, Hallas J. Assigning exposure duration to single prescriptions by use of the waiting time distribution. Pharmacoepidemiol Drug Saf. 2011;22(8):803-809.

29. Kuijer PM, Hutten BA, Prins MH, et al. Prediction of the risk of bleeding during anticoagulant treatment for venous thromboembolism. Arch Intern Med. 1999;159(5):457-460.

30. Gage BF, van Walraven C, Pearce L, et al. Selecting patients with atrial fibrillation for anticoagulation: stroke risk stratification in patients taking aspirin. Circulation. 2004;110:2287-2292.

31. Quan H, Sundararajan V, Halfon P, et al. Coding algorithms for defining comorbidities in ICD-9-CM and ICD-10 administrative data. Med Care. 2005;43(16):1130-1139.

32. Böttiger Y, Laine K, Andersson ML, et al. SFINX - a drug-drug interaction database designed for clinical decision support systems. Eur J Clin Pharmacol. 2009;65(6):627-633.

33. Hallinen T, Soini EJ, Asseburg C, et al. Warfarin treatment among Finnish patients with atrial fibrillation: retrospective registry study based on primary healthcare data. BMJ Open. 2014;4(2):e004071.

34. Helin T, Metso T, Lassila R, et al. INR testing results at the community clinics in the Hospital District of Helsinki and Uusimaa. Finn Med J. 2012;67:1569-1574.

35. Jones M, McEwan P, Morgan CL, et al. Evaluation of the pattern of treatment, level of anticoagulation control, and outcome of treatment with warfarin in patients with non-valvar atrial fibrillation: a record linkage study in a large British population. Heart. 2005;91(4):472-477.

36. Hallas J, Dall M, Andries A, et al. Use of single and combined antithrombotic therapy and risk of serious upper gastrointestinal bleeding: population based case-control study. BMJ. 2006;333(7571):726.

37. Vitry AI, Roughead EE, Ramsay EN, et al. Major bleeding risk associated with warfarin and co-medications in the elderly population. Pharmacoepidemiol Drug Saf. 2011;20(10):1057-1063.

38. Suh DC, Choi JC, Schein J, et al. Factors associated with warfarin discontinuation, including bleeding patterns, in atrial fibrillation patients. Curr Med Res Opin. 2013;29(7):761-767.

39. Linkins L, O’Donnell M, Julian JA, et al. Intracranial and fatal bleeding according to indication for long-term oral anticoagulant therapy. J Thromb Haemost. 2010;8(10):2201-2207.

40. Ilomäki J, Helin-Salmivaara A, Huupponen R, et al. Analgesic use before and after oral anticoagulant initiation - a population-based study in Finland. Eur J Clin Pharmacol. 2015;71(6):723-732.

41. Arnason T, Wells PS, van Walraven C, et al. Accuracy of coding for possible warfarin complications in hospital discharge abstracts. Thromb Res. 2006;118(2):253-262.

42. Forslund T, Wettermark B, Wändell P, et al. Risk scoring and thromboprophylactic treatment of patients with atrial fibrillation with and without access to primary healthcare data: experience from the Stockholm health care system. Int J Cardiol. 2013;170(2):208-214.

43. Rikala M, Hauta-Aho M, Helin-Salmivaara A, et al. Co-prescribing of potentially interacting drugs during warfarin therapy - a population-based register study. Basic Clin Pharmacol Toxicol. 2015;117(2):126-132. 


\section{Supplementary material}

Table SI Identification of bleeding events, indications, comorbidities, and medications

\begin{tabular}{|c|c|c|c|}
\hline $\begin{array}{l}\text { Bleeding events, indications, } \\
\text { comorbidities and medications }\end{array}$ & ICD-I 0 codes/procedure codes & Reimbursement codes & ATC codes \\
\hline \multicolumn{4}{|l|}{ Bleedings $^{\mathrm{a}}$} \\
\hline Intracranial & $160 *, 161 *, 162 *$ & & \\
\hline Gastrointestinal & $\begin{array}{l}\text { K920, K92 I, K922, I850, K22 I, K250, K252, } \\
\text { K254, K256, K260, K262, K264, K266, K270, } \\
\text { K272, K274, K276, K280, K282, K284, K286, } \\
\text { K290, K625 }\end{array}$ & & \\
\hline Other & $\begin{array}{l}\text { N02*, K66I, N938, N939, N950, R04I, } \\
\text { R042, R048, R049, R3I, R58, D683, } \\
\text { H356, H43I, H450, M250 }\end{array}$ & & \\
\hline \multicolumn{4}{|l|}{ Indications } \\
\hline Atrial fibrillation & 148*, FPD*, TFP46, TFP20 & 207 (based on 148) & \\
\hline Venous thrombosis & $180^{*}, 18 I^{*}, 182^{*}($ not $180 I)$ & & \\
\hline Mechanical heart valve & Z952*, FJ*, FK*, FM*, FG* & & \\
\hline Pulmonary embolism & $126 *$ & & \\
\hline Ischemic stroke/TIA & 163*, G45* & & \\
\hline \multicolumn{4}{|l|}{ Comorbidities } \\
\hline Coronary artery disease & $\begin{array}{l}120^{*}-125^{*} / \mathrm{FNA}^{*}, \text { FNB*, FNC*, FND*, FNE*, } \\
\text { FNIAT, FNIBT, FNIYT, TFN40, TFN50 }\end{array}$ & 206 & $\mathrm{COI}$ \\
\hline Heart failure & $150 *$ & 201 & \\
\hline Ischemic stroke/TIA & $163 *-166 *, \mathrm{G} 45^{*}$ & & \\
\hline Hypertension & $110 *-115 *$ & 205 & \\
\hline Peripheral arterial disease & $\begin{array}{l}\text { 170*, 174*/PFH*, PDQ*, PEQ*, PFQ*, } \\
\text { PFIAT, PFIBT, PEIAT, PEIBT }\end{array}$ & 211 & \\
\hline $\begin{array}{l}\text { Thrombosis in cerebral arteries } \\
\text { or in intracranial veins }\end{array}$ & $165^{*}, 166^{*}, 1676$ & & \\
\hline Diabetes & EIO*-EI4* & 103 & AlO \\
\hline Renal impairment & N04*, NI7*-NI9*, N258, Z49I, Z492 & $123,137,138,190,320$ & \\
\hline Liver disease & $\mathrm{K} 70 *-\mathrm{K} 77^{*}, \mathrm{BI} 5^{*}-\mathrm{B} 19 *, \mathrm{~B} 942$ & & \\
\hline Dementia & $\mathrm{F} 00^{*}, \mathrm{FOI} *, \mathrm{~F}^{2} 3^{*}, \mathrm{G} 30^{*}$ & 307 & N06D \\
\hline Malignancy & $\mathrm{C} 00 *-\mathrm{C} 99 *, \mathrm{D} 00 *-\mathrm{D} 09 *$ & $115-117,128,130$ & L0I*, L02B* (not LOIBAOI) \\
\hline Alcohol abuse & $\begin{array}{l}\text { E244, FI0*, G3I2, G405I, G62I, G72I, } \\
\text { I426, K292, K70*, K852, K860, R780, T5I0, } \\
\text { Y9II, Y9I2, Y9I3, Y9I9, Z502, Z7I4 }\end{array}$ & & N07BB \\
\hline Pulmonary disease & $\mathrm{J} 44^{*}-\mathrm{J} 46^{*}$ & 203 & R03 \\
\hline Rheumatic disease & M05*-M09*, MI3*, M3I*-M36*, M45*, M46* & $202,281,313$ & \\
\hline Gastrointestinal disease & $\begin{array}{l}\text { K2I*, K223, K25I, K253, K255, K257, } \\
\text { K259, K26I, K263, K265, K267, K269, } \\
\text { K27I, K273, K275, K277, K279, K28I, } \\
\text { K283, K285, K287, K289, K633 }\end{array}$ & & $\mathrm{A} 02 \mathrm{~B}$ \\
\hline \multicolumn{4}{|l|}{ Medications } \\
\hline Number of drugs & & & Number of different ATC-codes \\
\hline Any cardiovascular drug & & & $\mathrm{COI-C04,C07-C09}$ \\
\hline Antithrombotic drugs & & & $\mathrm{B} 0 \mathrm{I}$ (not BOIAA03) \\
\hline Lipid-modifying drugs & & & $\mathrm{ClO}$ \\
\hline
\end{tabular}

Notes: aData adapted from Gomes T, Mamdani MM, Holbrook AM, et al. Rates of hemorrhage during warfarin therapy for atrial fibrillation. CMAI. 20I3;I85(2):EI2I-EI27.1 Codes 19820, 1983, K6380, and K3180 were excluded as they do not appear in the Finnish ICD-10 codes. *Includes all the diagnoses from the given ICD-I0 code. Abbreviations: ATC, Anatomical Therapeutic Chemical; ICD, International Classification of Diseases; TIA, transient ischemic attack. 

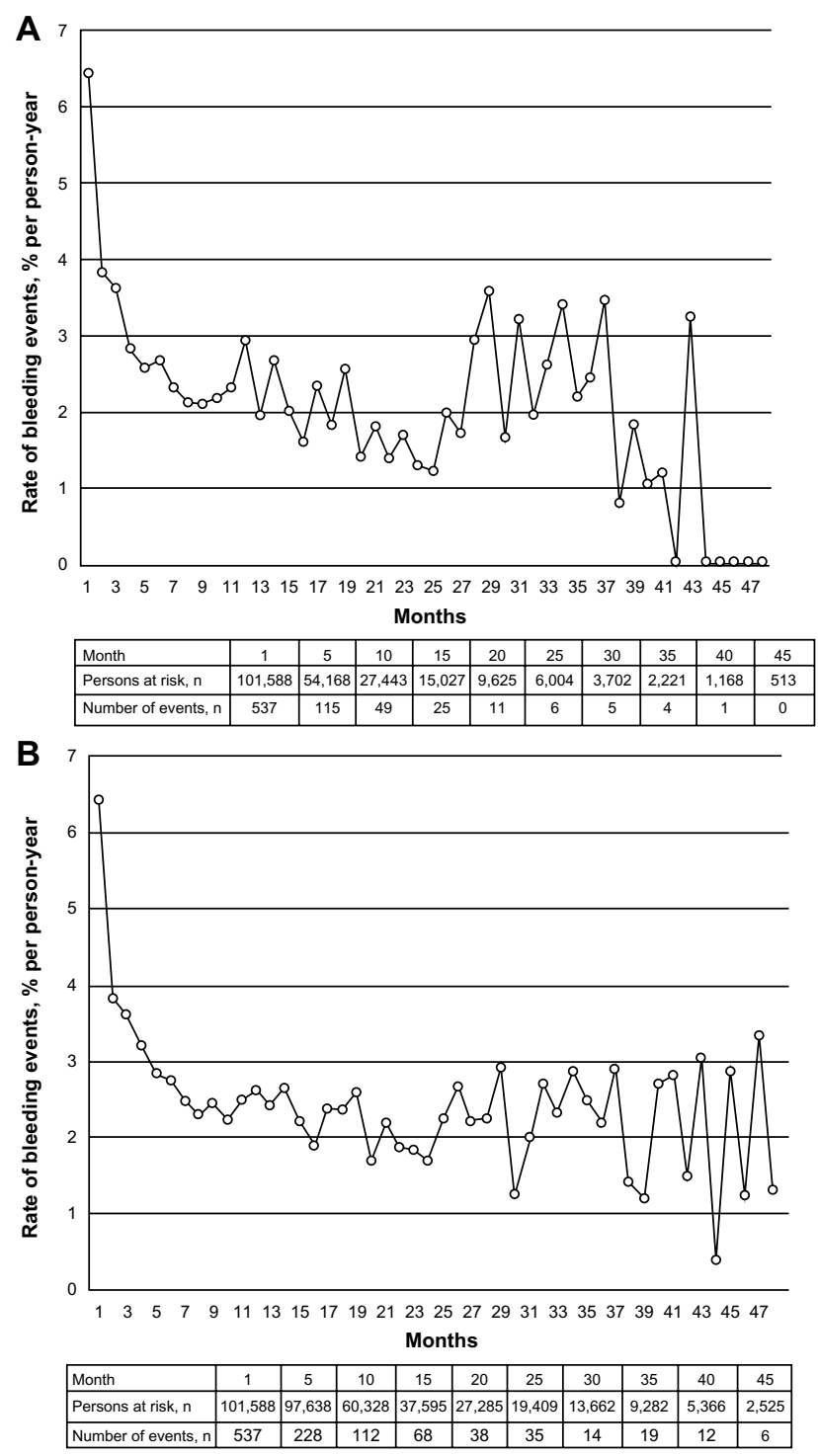

Figure SI Rate of bleedings requiring hospitalization for each month of the first warfarin episode when the episode was assumed to continue until the gap between consecutive dispensations exceeded III days (A) or 180 days (B).

\section{Reference}

1. Gomes T, Mamdani MM, Holbrook AM, et al. Rates of hemorrhage during warfarin therapy for atrial fibrillation. CMAJ. 2013;185(2): E121-E127.

\section{Publish your work in this journal}

Clinical Epidemiology is an international, peer-reviewed, open access, online journal focusing on disease and drug epidemiology, identification of risk factors and screening procedures to develop optimal preventative initiatives and programs. Specific topics include: diagnosis, prognosis, treatment, screening, prevention, risk factor modification, ogy \& biostatistical methods, and evaluation of guidelines, translational medicine, health policies \& economic evaluations. The manuscript management system is completely online and includes a very quick and fair peer-review system, which is all easy to use.

\section{Dovepress}

